Preprints of the

Max Planck Institute for

Research on Collective Goods

Bonn 2006/25

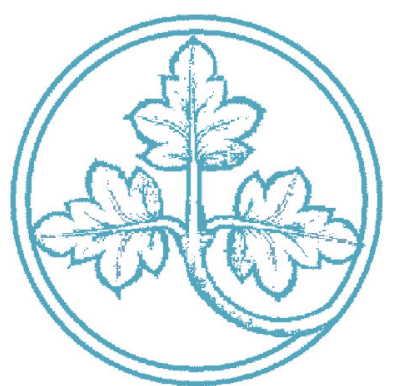

Cooperation in Symmetric and Asymmetric Prisoner's Dilemma Games

Martin Beckenkamp

Heike Hennig-Schmidt

Frank P. Maier-Rigaud

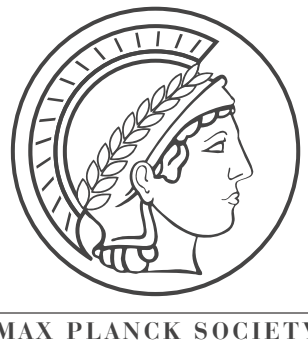




\section{Cooperation in Symmetric and Asymmetric Prisoner's Dilemma Games}

Martin Beckenkamp / Heike Hennig-Schmidt / Frank P. Maier-Rigaud

March 2007 


\title{
Cooperation in Symmetric and Asymmetric Prisoner's Dilemma Games*
}

\author{
Martin Beckenkamp ${ }^{\dagger} \quad$ Heike Hennig-Schmidt ${ }^{\ddagger}$ \\ Frank P. Maier-Rigaud ${ }^{\S}$
}

March 4, 2007

\begin{abstract}
We experimentally study the effect of asymmetry on cooperation in a 40 period prisoner's dilemma game in fixed partner design. We distinguish between a high and low payoff symmetric prisoner's dilemma and an asymmetric game combined out of both symmetric ones. Asymmetry significantly decreases cooperation, as low-type players are more likely to defect after mutual cooperation while high-type players initiate cooperation more often than the former. Asymmetry also has a significant negative effect on the stability of cooperation rendering long sequences of mutual cooperation extremely rare.
\end{abstract}

JEL-Classifications: C81, D70, C91.

Keywords: Symmetry, Asymmetry, Prisoner's Dilemma, Experiments.

*This paper has benefited from comments and suggestions received during presentations at the University of Bonn, the Max Planck Institute for Research on Collective Goods and the conference "Understanding Reciprocity" in Verbania 2007. In particular the authors would like to thank Christoph Engel, Johannes Kaiser, Andreas Niklisch, Elinor Ostrom, Reinhard Selten, and the Max Planck library team. Financial support from the European Union through the TMR research network ENDEAR (FMRX-CT98-0238) is gratefully acknowledged.

${ }^{\dagger}$ Max Planck Institute for Research on Collective Goods, Bonn, Germany, e-mail: beckenk@coll.mpg.de.

${ }^{\ddagger}$ BonnEconLab, Laboratory for Experimental Economics, University of Bonn, Germany, e-mail: hschmidt@uni-bonn.de.

$\S$ BonnEconLab, Laboratory for Experimental Economics, University of Bonn, Germany; Max Planck Institute for Research on Collective Goods, Bonn, Germany, e-mail: maierrigaud@microeconomics.de. 


\section{Introduction}

The prisoner's dilemma (PD) is an important model in economics, psychology, political science, sociology and biology as well as other disciplines for now over five decades. Previous PD experiments show that in contrast to theoretical predictions, cooperation rates are generally very high in the symmetric payoff variant of the game. The present paper studies cooperation in the PD in a more realistic scenario by systematically analyzing the effects of asymmetric payoffs.

Almost all studies investigating the PD are designed in such a way that payoffs are identical for both players. ${ }^{1}$ Asymmetry is, however, an important property of many economic and non-economic problems. Most real world interactions entail different outcomes for each player, even if all players choose cooperatively. ${ }^{2}$ The same obviously applies if all decide non-cooperatively. Already in the early nineties Murnighan et al. (1990, p.181) noted that "research has been inexplicably absent on the effects of asymmetry". The present study focuses on this much broader type of conflict expanding the limited and rather unsystematic research conducted in this area. We modified the symmetric payoff matrix in such a way that both the cooperation and the defection payoff for player $i$ is either larger or equal to that of player $j$. We therefore depart from the standard approach to study social interactions characterized by conditions of symmetry and equality. A systematic analysis of the asymmetric PD is not only a valuable addition to the existing (mostly symmetric) PD literature but it is also of particular relevance for understanding reciprocity, equity and fairness especially in light of recent theoretical developments based exclusively on symmetric experimental games (see, e.g., Fehr and Schmidt (1999) or Fehr and Schmidt (2003)). ${ }^{3}$

\footnotetext{
${ }^{1}$ See Flood (1958) for the first experimental analysis of the game that at the same time is also an exception to this rule.

${ }^{2}$ Asymmetry plays an important role in various areas spanning from, for instance, competition policy questions surrounding collective dominance or cartel stability issues (see Friederiszick and Maier-Rigaud (2007)) to governance questions surrounding collective action problems and the management of common-pool resources (see Ostrom (1990)).

${ }^{3}$ See also Hennig-Schmidt (2002) and de Jasay et al. (2004) for a critique of the "symmetry"
} 
An important implication of asymmetry is the increased complexity of the game that is likely to induce dynamics that are absent in symmetric settings. Referring to the classic strategy tournaments by Axelrod (1984), Murnighan (1991, p. 464) writes:

"Axelrod (1984) found that certain strategies (tit-for-tat) effectively train an opponent to choose cooperatively. As a result, both parties do well and the likelihood that they will fall into mutual non-cooperation is minimized. Axelrod posits that similar results as found in the two-person, symmetric, iterated games would follow from games that satisfy PD's requirements even if the players' payoffs differ. Findings on asymmetric PD's question the generality of Axelrod's claim."

According to Murnighan, asymmetric dilemmas require much more complicated negotiations than typical PD games. The dilemma no longer consists of a relatively simple choice between the risks of mutual cooperation and the regrets of mutual defection. The complexity of the game adds more dynamic considerations. Pairs who can implement schemes of alternations do much better in increasing their payoffs while simultaneously reducing the temptation to defect. As a result, the main hypothesis of this paper is that asymmetry reduces cooperation rates. Asymmetry also adds to the problem of cooperation the problem of reaching a mutual understanding of what a desirable outcome is. Given these considerations and given relatively stable and high cooperation rates in symmetric iterated PD games, the main hypothesis of this paper is that asymmetry reduces cooperation.

Asymmetry in PD games is not a well-defined concept, though. There is not only an infinite number of combinatorial possibilities but asymmetry can also be introduced in some cells only or in a design where no player has consistently higher payoffs than the other in each cell (c.f. Murnighan et al. (1990), and Murnighan approach. 
and King (1992)). Finally, including negative payoffs adds an additional factor. ${ }^{4}$ As the review of the literature on asymmetric PD games in Section 3 will show, cooperation rates are not easily comparable: not only do the payoff parameters vary across studies but also the number of repetitions, the matching protocol, the remuneration and the justification for the asymmetry presented to participants. As Lave (1965) and others have shown, these factors can have an important influence on cooperation rates.

Given the problems of comparability, we chose a comprehensive experimental design to systematically compare behavior in symmetric and asymmetric situations (SYM, ASYM respectively) and to study the impact of asymmetry on dyad-level dynamics.

We analyze two symmetric and one asymmetric PD game played repeatedly with a fixed opponent over 40 periods under perfect information. In SYM, we consider two symmetric treatments with HIGH and LOW payoffs for both players where LOW $=\frac{2}{3}$ of HIGH. ASYM is an asymmetric combination of both symmetric games where player $i$ gets the high payoff and player $j$ the low payoff of the SYM treatments.

We observed $70.00 \%$ cooperation in LOW, $59.17 \%$ in HIGH and $38.75 \%$ in ASYM, a substantial difference between treatments. Cooperation patterns remain unstable roughly until period 10 before stabilizing at a rather high level of about $80 \%$ in LOW, and $65 \%$ in HIGH. In ASYM, cooperation gradually rises to about $55 \%$. The general finding that cooperation is increasing over time is in line with other studies (Rapoport and Chammah (1965), Lave (1965), Murnighan and King (1992), Brenner and Hennig-Schmidt (2006)).

As hypothesized, asymmetry indeed substantially decreases cooperation rates, pointing towards the higher complexity of the game, whereas symmetry has a positive effect on mutual cooperation. We also find that high-type players initiate

\footnotetext{
${ }^{4}$ According to Kahnemann and Tversky (1979) and Tversky and Kahnemann (1981), negative payoffs can have a substantial impact.
} 
cooperation more often than low-type players. Defection by low-type players, possibly motivated by the aim to equalize payoffs, is more readily tolerated by high-type players. With respect to the stability of cooperation, we find that asymmetry has a negative impact rendering long sequences of mutual cooperation extremely rare. Low-type players are more likely to defect after mutual cooperation than high-type players.

In addition to the hypothesized effect of asymmetry on cooperation, we also find that the stability of mutual cooperation under symmetry is higher once it has been reached, i.e. mutual cooperation $(C C)$ is followed by $C C$ more often in SYM than in ASYM.

The remainder of the paper is organized as follows. Section 2 presents the games studied. Section 3 reviews the relevant experimental literature on symmetric PDs and the limited experimental literature on asymmetric PDs. Section 4 gives a detailed description of the experimental design and the experimental protocol. Section 5 presents the results and section 6 concludes with a discussion of the main findings.

\section{The Prisoner's Dilemma Game}

Table 1 presents a typical 2-player matrix game in normal form. This game is a PD if and only if the following conditions are met for both player $i$ 's and $j$ 's payoffs:

$$
a>b>c>d
$$

and

$$
2 b>a+d
$$


Table 1: General $2 \times 2$ prisoner's dilemma game in normal form $(\mathrm{PD}){ }^{6}$

\begin{tabular}{l|cc} 
& Cooperate & Defect \\
\hline \hline Cooperate & $\left(b_{i}, b_{j}\right)$ & $\left(d_{i}, a_{j}\right)$ \\
Defect & $\left(a_{i}, d_{j}\right)$ & $\left(c_{i}, c_{j}\right)$
\end{tabular}

The second condition goes back to Rapoport and Chammah (1965, p. 34) who proposed it in the context of iterated (symmetric) PD's in order to eliminate the possibility of simple alternation between $D C$ and $C D$ providing higher payoffs than mutual cooperation thus removing the dilemma. ${ }^{5}$

The formal presentation in table 1 is more general than the presentations usually found because it also accounts for asymmetric payoffs. In symmetric games, the indexed payoffs are equivalent to each other such that e.g. $a_{i}=a_{j}=a$ $\vee i \neq j$.

It is well known that both players defecting is the unique Nash equilibrium of the one-shot PD game. Applying the logic of backward induction, Luce and Raiffa (1957) showed that the unique Nash-equilibrium outcome in the finitely repeated $\mathrm{PD}$ game under perfect information is again the one in which both players defect in every single period. In fact, the unique subgame-perfect equilibrium is both players defecting in all periods. ${ }^{7}$

The general formulation of the PD makes no restriction as to symmetry or asymmetry of players' payoffs. The asymmetric PD can be operationalized in many ways as long as at least one of the payoffs $a_{i}$ to $d_{i}$ differs from $a_{j}$ to $d_{j}$ in table 1 . Our present study assumes $a_{i}>a_{j}, b_{i}>b_{j}, c_{i}>c_{j}, d_{i}=d_{j}$, that is, the

\footnotetext{
${ }^{5}$ There exist several experimental studies with iterated PD games that violate this assumption and thereby no longer allow a separation of effects due to asymmetry or payoff maximization through simple alternations. In the experiment by Lave (1965) and by McKeown et al. (1967) the condition is violated for one of the players. Murnighan et al. (1990) and Murnighan and King (1992) implement so-called asymmetric dilemmas knowing that a subset of the games discussed violates the condition either for one or for both players.

${ }^{6}$ Note that the first element of the payoff vectors refer to the row player.

${ }^{7}$ For an overview of the theoretical literature see Binmore (1992) or Osborne and Rubinstein (1994).
} 
payoffs of player $j$ are $2 / 3$ of the payoffs of player $i$. The parameters are given in table 2 .

Table 2: Experimental parameters.

\begin{tabular}{|c|c|c|}
\hline & \multicolumn{2}{|c|}{ HIGH } \\
\hline & Cooperate & Defect \\
\hline Cooperate & $(12,12)$ & $(0,18)$ \\
\hline \multirow[t]{3}{*}{ Defect } & $(18,0)$ & $(6,6)$ \\
\hline & \multicolumn{2}{|c|}{ LOW } \\
\hline & Cooperate & $\overline{~ D e f e c t}$ \\
\hline Cooperate & $(8,8)$ & $(0,12)$ \\
\hline \multirow[t]{3}{*}{ Defect } & $(12,0)$ & $(4,4)$ \\
\hline & \multicolumn{2}{|c|}{ ASYM } \\
\hline & Cooperate & Defect \\
\hline Cooperate & $(12,8)$ & $(0,12)$ \\
\hline Defect & $(18,0)$ & $(6,4)$ \\
\hline
\end{tabular}

\section{Experimental Research on Symmetric and Asym- metric PDs}

Almost all studies investigating the PD analyze symmetric situations and only few studies are devoted to asymmetric settings. In the following subsection, we first refer to some relevant experimental work on symmetric PDs. In subsection 3.2 , we will give an overview of the experimental literature on asymmetric PD games.

\subsection{Experimental Research on Symmetric PDs}

Rapoport and Chammah (1965) conducted a series of laboratory experiments in which participants played a PD game repeated over 300 periods. Depending on 
the parameters of the game, overall cooperation rates varied between 26.8 and $77.4 \%$. The authors found mutual cooperation in $53 \%$ of all dyads and more than $23 \%$ in the last 25 periods. Mutual defection took place in $17 \%$ of the dyads. Cooperation in the first period varied between 45 and $70 \%$ decreasing in the second period to $35-65 \%$. Inquiring into the dynamics of the decision process, Rapoport and Chammah found cooperation waning in the first half of the experiment. Thereafter, cooperation increased to roughly the level at the beginning of the experiment with mutual cooperation rising steadily. The authors attribute this phenomenon to the fact that "Learning goes both ways in Prisoner's Dilemma. First the subjects learn not to trust each other; then they learn to trust each other" (p. 201).

Studies on the PD with a much lower number of periods and restart effects show that average cooperation levels start relatively high between 40\%-60\%; and then gradually decline over time.

Selten and Stoecker (1986) investigated behavior in a prisoner's dilemma game where 35 participants played 25 supergames consisting of a ten-period PD in stranger design. ${ }^{8}$ The most common pattern of behavior was initial periods of mutual cooperation followed by an initial defection that was then followed by noncooperation in the remaining periods. The authors also find players exhibiting end effect play. The end effect is defined as at least four consecutive periods of mutual cooperation with no further cooperation following the first defection thereafter. A very striking result is the emergence of the first defection. Players start to defect earlier and earlier in subsequent supergames so that cooperation unravels from the end. ${ }^{9}$

Andreoni and Miller (1993) analyze a 10-period PD in partner design repeated 20 times with changing the co-player each repetition. ${ }^{10}$ They also study how

\footnotetext{
${ }^{8}$ Parameters are $a_{i}=a_{j}=145, b_{i}=b_{j}=60, c_{i}=c_{j}=10, d_{i}=d_{j}=-50$.

${ }^{9}$ For an extensive discussion of the paper see Roth (1995).

${ }^{10}$ Parameters are $a_{i}=a_{j}=12, b_{i}=b_{j}=7, c_{i}=c_{j}=4, d_{i}=d_{j}=0$.
} 
people behave if they have a 50/50 chance to meet a computer player playing a tit-for-tat strategy. Average cooperation rates start relatively high at around $60 \%$ and subsequently decrease until a sharp end effect is observed. Looking at the first period of defection over the 20 supergames there is a clear tendency for cooperation to last until later periods.

Maier-Rigaud and Apesteguia (2006) analyze a 20-period PD in partner design. ${ }^{11}$ Average cooperation started at almost $70 \%$ and declined to below $30 \%$ in the first three periods. It rose to approximately $60 \%$ and then declined more or less steadily throughout the game to approximately $20 \%$ in the last period. Overall cooperation was $33 \%$.

For surveys of the experimental literature on symmetric PD games, see Lave (1965), Rapoport and Chammah (1965), Oskamp (1971), Roth and Murnighan (1978), Roth (1995) and Ledyard (1995).

Despite the high number and large variation in experiments implementing the symmetric PD game our results are generally in line with the cooperation rates, the development of cooperation and the end game behavior found in that literature.

\subsection{Experimental Research on Asymmetric PDs}

There is only a small literature on asymmetric PD games exhibiting a substantial variation in experimental conditions. ${ }^{12}$

Schellenberg (1964) ran symmetric and asymmetric experiments. ${ }^{13}$ Two series of experiments of 20 periods each were conducted where participants were rewarded by course credit.

\footnotetext{
${ }^{11}$ Parameters are $a_{i}=a_{j}=400, b_{i}=b_{j}=300, c_{i}=c_{j}=100, d_{i}=d_{j}=0$.

${ }^{12}$ The first PD experiment by Flood and Dresher (c.f. Flood (1958)) assumed asymmetry in the diagonal and in $d$, i.e. $b_{i} \neq b_{j}, c_{i} \neq c_{j}, d_{i} \neq d_{j}$, but $a_{i}=a_{j}$, i.e. $a_{i}=a_{j}=-1, b_{i}=0.5$, $b_{j}=1, c_{i}=0, c_{j}=0.5, d_{i}=1, d_{j}=2$.

${ }^{13}$ Parameters are $a_{i}=a_{j}=5, b_{i}=b_{j}=3, c_{i}=c_{j}=1, d_{i}=d_{j}=0$ in the symmetric treatment. Asymmetry was obtained by multiplying the payoffs of one of the players by two, i.e. $a_{i}=10, a_{j}=5, b_{i}=6, b_{j}=3, c_{i}=2, c_{j}=1, d_{i}=d_{j}=0$.
} 
In the first series of experiments, participants played against "stooges" that either followed an initially cooperative and increasingly non-cooperative strategy or an initially non-cooperative and increasingly cooperative strategy. The main finding based on the first series of experiments is that participants are more cooperative in the high-type player role and less cooperative in the low-type player role in the asymmetric game, the symmetric baseline game yielding cooperation rates in-between. In the series of experiments where no "stooges" were used Schellenberg did not find higher cooperation rates for high-type players. Schellenberg explains this interaction effect by the low cooperation of low-type players compared to the baseline. The second series of experiments did not yield statistically significant differences between symmetric and asymmetric games.

Sheposh and Gallo (1973) ran symmetric and asymmetric experiments. ${ }^{14}$ Participants played for real money. The authors hypothesized cooperation in the asymmetric treatment to be less than in the symmetric treatment. In particular, low levels of cooperation were expected from participants with lower payoffs as minimal cooperative play is the only option to minimize payoff disparity.

80 participants played the game for 50 periods with feedback information on payoffs in each period.

The asymmetric game produced less cooperative behavior than the symmetric game (31.1\% vs. $39.2 \%)$. Low-type players cooperated significantly less than high-type players (25.1\% vs. $37.1 \%)$.

The authors then conducted a data analysis in terms of the conditional probabilities of one player's response in a given period as a function of the other player's choice in the preceding period. Were participants concerned with relative outcomes and did they try to avoid being surpassed by the other player? The smaller amount of cooperation in the asymmetric treatment was attributable to the sig-

\footnotetext{
${ }^{14}$ The parameters in the symmetric treatments are $a_{i}=a_{j}=5, b_{i}=b_{j}=4, c_{i}=c_{j}=1(-2)$, $d_{i}=d_{j}=0(-3)$. Asymmetry was obtained by multiplying the payoffs of one of the players by three, i.e. $a_{i}=5, a_{j}=15, b_{i}=4, b_{j}=12, c_{i}=1(-2), c_{j}=3(-6), d_{i}=0(-3), d_{j}=0(-9)$.
} 
nificantly lower proportion of cooperative moves by participants in the low-type position. Sheposh and Gallo's tentative interpretation is that participants' concern centered on the relative payoff rather than absolute personal gain. Low-type players consequently avoided cooperative play in order to reduce other's actual payoffs. Participants were less concerned with the notion of increasing their own payoffs than with redressing the imbalance caused by the asymmetrical structure of the game. ${ }^{15}$

Talley (1974) conducted several experiments with 168 participants each under various combinations of asymmetry and information. Asymmetry was created as in Sheposh and Gallo (1973) by multiplying the payoffs of one of the players by three. Treatments varied also with respect to information concerning others' payoffs, i.e. symmetry or asymmetry was not always known. Results indicated that full information enhanced cooperation in the symmetric games, while it reduced cooperation in the asymmetric games. In particular, lower overall cooperation in the asymmetric game was attributable to lower amounts of cooperation by low-type players.

Croson (1999) compared behavior in a symmetric and an asymmetric PD game. 80 participants were divided into 4 treatments, two of them involving a regular symmetric PD game and two an asymmetric one. ${ }^{16}$ Participants played 5 games each, 2 of them being the above mentioned PD games in a stranger design. Croson considers asymmetry in all cells, i.e. $a_{i}>a_{j}, b_{i}>b_{j}, c_{i}>c_{j}, d_{i}>d_{j}$. Participants were informed about their payoffs at the end of each period and were paid at the end of the session. Cooperation in the symmetric treatment was rather

\footnotetext{
${ }^{15}$ This is our reading of the paper because the claim that "subjects were concerned less with the notion of winning more money than their opponent than with the notion of preventing their opponent from surpassing them" (p. 332) is unclear. It is not clear how low-types could avoid being surpassed by high-type players without defecting. Not being surpassed is a first step for low-types on the way to higher relative profits and the two motives can therefore not be distinguished.

${ }^{16}$ Parameters are $a_{i}=a_{j}=85, b_{i}=b_{j}=75, c_{i}=c_{j}=30, d_{i}=d_{j}=25$ in the symmetric and $a_{i}=95, a_{j}=75, b_{i}=85, b_{j}=65, c_{i}=40, c_{j}=20, d_{i}=35, d_{j}=15$ in the asymmetric game.
} 
high with $77.5 \%$. Cooperation in the asymmetric treatment was lower amounting to $62.5 \%$. There was, however, no significant difference between high-type and low-type players.

The next papers focus on asymmetry without comparison to symmetric situations.

Murnighan et al. $(1990)^{17}$ conducted a series of asymmetric dilemma experiments only a few of which were asymmetric PD‘s. ${ }^{18}$

Participants in the experiment were students whose course credit depended on their performance in the game. No monetary payments were involved. Participants in three studies played in three-person groups and subsequently as individuals. They were allowed to exchange anonymous messages after the second period. The groups played the game between 8 and 20 periods, not knowing beforehand when the game would be terminated. ${ }^{19}$ Based on our calculations, overall cooperation was $54 \%$. Excluding the game where player type could not be consistently defined over all cells, low-type groups defected $45 \%$ and high-type groups $55 \%$ of the time.

In Murnighan and King (1992), nine different asymmetric dilemmas are considered only three of which fulfill the iterated PD condition and consequently are asymmetric PD games. ${ }^{20}$ Participants had full information on all outcomes and communication was allowed. Based on our calculations, and aggregated over all three asymmetric PDs, cooperation rates were $64 \%$ over the first 8 periods ( $84 \%$

\footnotetext{
${ }^{17}$ The experiment and the results are also reported in King and Murnighan (1988) and in Murnighan (1991).

${ }^{18}$ All asymmetric PD games involved identical off-diagonal cells with $a_{i}=a_{j}=40$ and $d_{i}=d_{j}=0$. One game implements $b_{i}>b_{j}$, with $b_{i}=32$ and $b_{j}=21$ but $c_{i}<c_{j}$, with $c_{i}=2, c_{j}=19$ and the other three $b_{i}>b_{j}$ and $c_{i}>c_{j}$ with $b_{i}, c_{i}=30,24 ; 24,22 ; 28,24$ and $b_{j}, c_{j}=28,20 ; 22,4 ; 24,4$ respectively. The respective games are Game 2 and 3 from the second experiment and Game 8 from the third. The game where player type could not be consistently defined over all cells is Game 4 of the second experiment.

${ }^{19}$ Note that the probabilistic nature of the game also affects the game theoretic prediction.

${ }^{20}$ All three games (called HIGH/HIGH in the paper) involved identical off-diagonal cells with $a_{i}=a_{j}=40$ and $d_{i}=d_{j}=0$. One game implements $b_{i}>b_{j}$, with $b_{i}=36$ and $b_{j}=24$ but $c_{i}<c_{j}$, with $c_{i}=18, c_{j}=20$ and the other two $b_{i}>b_{j}$ and $c_{i}>c_{j}$ with $b_{i}, c_{i}=36,4 ; 36,32$ respectively and $b_{j}, c_{j}=24,20$ each time.
} 
if the first two periods are excluded).

In Charness et al. (2007), asymmetric PD games are discussed although the focus of the paper is on two-stage modified PD games (coordination games) consisting of a first round where players simultaneously choose binding non-negative amounts to reward the counterpart for cooperation and a second round consisting of an asymmetric PD game. Aggregate cooperation rates in the three control sessions not containing a first stage compensation mechanism are 15.8\%, 17.5\% and $10.8 \%$ for Game 1, 2 and 3 respectively. ${ }^{21}$ Player types and pairing were randomized in each of the 25 periods of the game.

In Andreoni and Varian (1999), the first analysis of compensation mechanisms in the $\mathrm{PD}$, the experiment consists of a 15-period asymmetric $\mathrm{PD}$ game ${ }^{22}$ (in a give-some, take-some decomposition) followed by 25 periods of a two-stage modified PD game. ${ }^{23}$ The aggregate cooperation rate in the relevant first 15 periods is $25.8 \%$. Cooperation rates, however, differ significantly by player type. Players in the low-type position cooperate $16.7 \%$ of the time while the cooperation rate of high-types is $29.2 \%$.

The next papers analyze asymmetric dilemma games that violate the iteration condition. Although technically not PD games, a brief discussion of the main findings is relevant to the present study given the alternation patterns observed.

Lave (1965) ran a symmetric and an asymmetric experiment where asymmetry was obtained by multiplying the payoffs of one of the players by 2.5 in case of mutual cooperation. ${ }^{24}$ Participants played for 50 consecutive periods and no communication was allowed. Even though computer players were used in some

\footnotetext{
${ }^{21}$ The parameters are $a_{i}=52, a_{j}=60, b_{i}=40, b_{j}=52, c_{i}=28, c_{j}=24$ and $d_{i}=d_{j}=8$ for Game $1, a_{i}=40, a_{j}=60, b_{i}=32, b_{j}=52, c_{i}=20, c_{j}=24, d_{i}=4$ and $d_{j}=8$ for Game 2 and $a_{i}=52, a_{j}=44, b_{i}=44, b_{j}=36, c_{i}=32, c_{j}=28, d_{i}=8$ and $d_{j}=0$ for Game 3 .

${ }^{22}$ The parameters are $a_{i}=9, a_{j}=11, b_{i}=6, b_{j}=7, c_{i}=3, c_{j}=4$ and $d_{i}=d_{j}=0$.

${ }^{23}$ Note that the end of the game was presented as probabilistic (15-25 periods) in the instructions, thereby affecting the game theoretic predictions. Furthermore, players were rematched every period.

${ }^{24}$ The parameters are $a_{i}=a_{j}=10, b_{i}=2, b_{j}=5, c_{i}=c_{j}=-3, d_{i}=d_{j}=-5$.
} 
of the treatments, participants were paired with each other in the asymmetric sessions. Lave found a decline of cooperation from $57.5 \%$ to $50 \%$ when comparing the symmetric with the asymmetric treatment.

Analyzing individual behavior, Lave observed three cooperation strategy patterns. In the first one, participants stayed with the $\mathrm{CC}$ pattern and were not concerned about asymmetry. In the second pattern, participants alternated between $C D$ and $D C$ to get an expected value of 2.5 each. Finally, one pair settled on the optimal way of gaining equal payoffs: they played $\mathrm{CC}$ for five periods and $\mathrm{DC}$ in the sixth period achieving an expected value of $\frac{10}{3}$. In most cases, however, participants apparently failed to understand each others' signals and had great difficulties to settle on some stable cooperation strategy. Lave read participants' choices as being concerned about equal payoffs. They tried to achieve equality even though they had to pay a great deal of money to do so. ${ }^{25}$ With costly unilateral defection $(d<0)$, and asymmetry in the CC cell $\left(b_{j}>b_{i}\right)$, alternating patterns became very salient for participants concerned about equal payoffs.

According to the global summary of results in Murnighan et al. (1990), in particular taking into account the 10 additional games not being PD's, participants rarely fell into a deficient series of non-cooperative outcomes. They instead used the off-diagonal payoffs to increase the outcome of the low player by simple or complex patterns of alternation. They implemented what Pruitt (1981) termed "integrative solutions". The low-type player $j$ chose cooperatively most of the time, yet defecting regularly. This was tolerated by the high-type player $i$ who chose cooperatively in every period. Thus, they jointly gained more than they would otherwise have been able to had they decided competitively. Murnighan (1991) states that arriving at complex alternation patterns requires a series of cognitive discoveries. Players that do not loose much if both players defect must first discover their "power" and realize how to use it to increase their payoffs.

\footnotetext{
${ }^{25}$ That participants in experiments may be willing to do so has also been shown by Güth et al. (2003).
} 
If they succeed to establish such a pattern of complex alternation they also establish less temptation for either player to defect because they both would loose. Implementing complex integrative solutions was certainly facilitated by allowing players to communicate. This was further corroborated by Murnighan and King (1992), who found that cooperation was rare when communication was not allowed. Providing bargainers with information on possible strategies was clearly important for evoking alternations. Discovering complex alternation schemes was difficult. Once discovered and implemented, complex alternation was stable. Defections were rare compared to mutual cooperation.

McKeown et al. (1967) conducted an experiment operationalizing asymmetry in all but the CC cell, with $a_{i}>a_{j}, b_{i}=b_{j}, c_{i}>c_{j}, d_{i}>d_{j} .{ }^{26}$ Participants received feedback on the scores of every single period but did not get a cumulative score. Participation in the experiment fulfilled course requirement, thus no monetary payments were involved. Participants first played in the low-type position and then in the high-type position against a dummy over 100 trials. It was stressed in the instructions that they were playing in the weaker/stronger position. Their analysis showed that when participants are in the role of the low-type player, they are significantly more cooperative than in the role of the high-type player. Given that payoffs in the $C C$ cell remain the same, such a result could also be explained by the fact that $D D$ results in higher relative payoffs for the high-type player. In addition, the low- and high-type position was switched during the game, rendering complex patterns unnecessary to recalibrate outcomes.

Overall the number of asymmetric PD games analyzed experimentally is extremely limited. Most studies do not establish symmetric benchmarks, suffer from insufficient independent observations or involve pre-programmed strategies

\footnotetext{
${ }^{26}$ The parameters are $a_{i}=110, a_{j}=200, b_{i}=b_{j}=100, c i=-150, c_{j}=50, d_{i}=-200$, $d_{j}=20$. Note that for consistency, we reversed the labels of player $i$ and $j$. In McKeown et al. (1967) the $i$ player was the low-type player.
} 
rendering general conclusions on the effects of asymmetry difficult. The following section presents a comprehensive experimental design aimed at systematically comparing behavior in a symmetric and an asymmetric PD setting.

\section{Experimental Design}

Our experiment is based on a $3 \times 1$ design running two symmetric (SYM) payoff treatments $(\mathrm{HIGH})$ and $(\mathrm{LOW})$ and one asymmetric treatment (ASYM). See table 2 for the payoffs chosen in our design. ${ }^{27} \mathrm{HIGH}$ is the normal form game already studied by Pruitt (1967) and Pruitt (1970) with $a_{i}=a_{j}=18, b_{i}=b_{j}=$ $12, c_{i}=c_{j}=6$, and $d_{i}=d_{j}=0$. LOW is characterized by generally lower payoffs with $a_{i}=a_{j}=12, b_{i}=b_{j}=8, c_{i}=c_{j}=4$, and $d_{i}=d_{j}=0$.

In both treatments, $b=2 c$, and $a=3 c$. Moreover, $\frac{a_{H I G H}}{a_{L O W}}=\frac{b_{H I G H}}{b_{L O W}}=\frac{c_{H I G H}}{c_{L O W}}=$ $\frac{3}{2}$. ASYM is the asymmetric game where player $i$ (player $j$ ) has the same payoffs as both players have in HIGH (LOW). In that sense, ASYM is a composition of both symmetric games.

The experiment was conducted at the Experimental Laboratory of the University of Bonn. It was programmed in z-Tree (Fischbacher (1999)) using a modified version of the program by Maier-Rigaud and Apesteguia (2006). At the beginning of each session, participants were randomly assigned to one of the 18 computer terminals. Before the session started, participants first had to read the instructions (see Appendix B), and then had to answer test questions to check if they understood the game they were about to participate in (see Appendix C). The experiment was started once all participants had correctly answered all test questions. On the decision screen participants could see the game in normal form, that is the two choice options A and B, their own highlighted payoffs and the payoffs of their counterpart (see Appendix B). Feedback information on own

\footnotetext{
${ }^{27}$ In all experiments we used the neutral labels A and B, instead of cooperate and defect and the requirements for iterated PD's were satisfied (equation 2 above).
} 
choice, choice of the other, period, remaining periods and payoff in the period as well as total payoff was given after every period. At the end of the experiment participants had to give reasons for their decisions in a questionnaire (see Appendix D).

In all treatments, it was common knowledge that participants played the same game against the same opponent for 40 periods. In each treatment, we had nine independent observations. ${ }^{28}$ We chose 40 periods in partner design to enable the development of cooperation over time. In particular, we wanted to study whether asymmetry continues to be relevant in later periods of the game or whether it can be viewed as an initial complication loosing importance over time.

A total of $2 \times 9 \times 3=54$ students mainly majoring in law or economics participated in the experiment. The experiment took 40 minutes on average. Taler (the experimental currency) were transformed into Euro at the exchange rate of 1 Taler $=€ 0.04 .{ }^{29}$ The average payoff over all treatments was $€ 12.44 .{ }^{30}$

\section{Results}

\subsection{Cooperation Rates over Time}

Over all periods, we observe $70.00 \%$ cooperation in LOW, $59.17 \%$ in $\mathrm{HIGH}$ and $38.75 \%$ in ASYM. We found unstable patterns of cooperation and defection until roughly period 10 with cooperation in ASYM declining to 15\%. Cooperation then stabilizes at a rather high level of about $80 \%$ in LOW, and $65 \%$ in HIGH. In ASYM, cooperation gradually rises to about $55 \%$ until period 33 . In all treat-

\footnotetext{
${ }^{28}$ Throughout the paper, the two players playing together over the 40 periods are also termed a dyad or a group.

${ }^{29}$ At the time the experiment was run $€ 1$ roughly corresponded with $\$ 1$. Purchasing power was, however, higher.

${ }^{30}$ Average payoffs range from $€ 10.92$ in LOW, $€ 11.06$ in ASYM to $€ 15.33$ in HIGH. Lowtype players received on average $€ 9.28$ and high-types $€ 12.85$. In comparison to payoffs under mutual cooperation low-types achieved $72.5 \%$ and high-types $66.9 \%$ compared to $85.3 \%$ in LOW and $79.8 \%$ in HIGH.
} 
ments, we see an end effect starting in period 38 (see figure 1).

Figure 1: Cooperation rates in ASYM, LOW and HIGH.

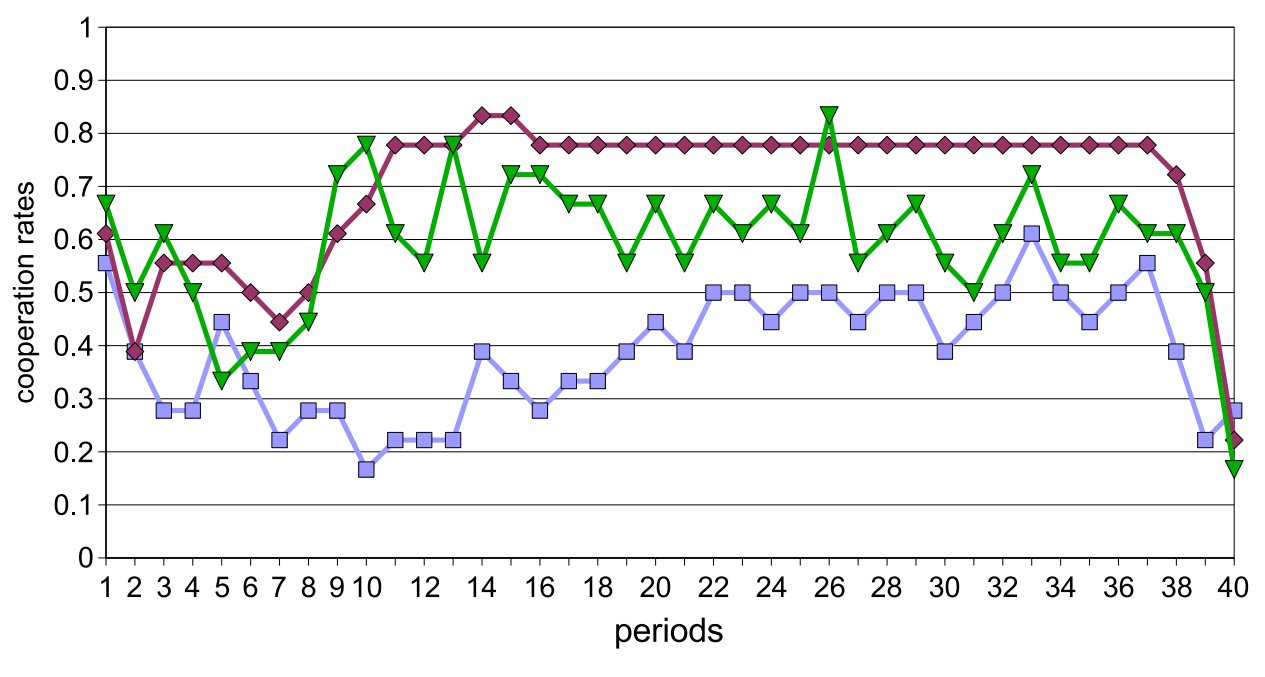

$\mathrm{ASYM} \diamond \mathrm{LOW} \nabla \mathrm{HIGH}$

Aggregated over all treatments $(3 \times 9=27$ independent observations), cooperation amounts to $61.11 \%$ in period 1, declining to $42.59 \%$ in period 2. After period 8 , cooperation recovers and varies around $60 \%$ until period 38 . In the last two periods, we observe the well-known end-game effect.

Appendix A gives a detailed account of all dyads in all three treatments. Stability of cooperation is higher in the symmetric treatments (HIGH and LOW) than in ASYM. Long-lasting cooperating dyads are characterized by long ranges on the CC-line, i.e. on the x-axis. The stability of the cooperation rate in LOW from period 16 to 37 in figure 1 is due to polarization. Appendix A shows that these periods are characterized either by mutual cooperation (7 dyads) or defection (2 dyads).

Long sequences of mutual cooperation (i.e. more than 20 periods) are extremely rare in ASYM (1 dyad). The idea that mutual cooperation is less desirable in ASYM also shows up in the answers given in the final questionnaire. As a reason for the choices made, one player for instance states: "Alternating between 
A and B was the most effective decision for both players." Another participant states the goal "to maximize profits under the condition that both players receive equal payoffs".

\subsection{Comparison of Cooperation Rates}

In this subsection, we are interested in how asymmetry affects cooperation. It has been pointed out in the literature that players may try to even out the asymmetric payoff structure and aim for equal payoffs (Lave (1965), Murnighan et al. (1990), Murnighan and King (1992), and de Herdt (2003)). If this were indeed the case for both players then a complicated alternation strategy of full cooperation for the high-type player $(i)$ and defection of the low-type player $(j)$ on every fourth move should be observed. But even if such a complicated pattern is not observed players may (try to) alternate between cooperation and defection to get more equal payoffs than by mere cooperation and higher payoffs than by mutual defection. Such behavioral patterns would lead to lower cooperation rates in ASYM. We therefore hypothesize that asymmetry leads to lower cooperation rates.

RESULT 1: Asymmetry leads to lower cooperation rates.

SUPPORT: Pooling the data of the symmetric conditions LOW and HIGH and comparing it to ASYM, we find that cooperation rates in ASYM are substantially lower. A Mann-Whitney U test, comparing the cooperation rates in the respective 9 ASYM and 18 SYM groups results in a significant finding ( $p \leq 0.047$; onesided). An additional Mann-Whitney U test for a detailed comparison yields that cooperation in LOW is significantly higher than in ASYM $(p \leq 0.047$; onesided) ${ }^{31}$

\footnotetext{
${ }^{31} \mathrm{~A}$ similar result is obtained using a Fisher-Pitman permutation test yielding a significant result for SYM vs. ASYM ( $p \leq 0.035$; one-sided) and for LOW vs. ASYM ( $p \leq 0.031$; onesided). HIGH vs. ASYM yields ( $p \leq 0.095$; one-sided) and no significant result is obtained comparing LOW vs. HIGH ( $p \leq 0.519$; two-sided). See Kaiser (2007) for a description of the Fisher-Pitman test.
} 
Table 3: Strategic interactions in HIGH (frequencies).

\begin{tabular}{|c|c|c|c|c|c|c|}
\hline \multirow[t]{2}{*}{ dyad } & \multicolumn{4}{|c|}{ followed by } & \multirow[t]{2}{*}{ 40th period } & \multirow[t]{2}{*}{ Sum } \\
\hline & $\mathrm{CC}$ & $\mathrm{CD}$ & $\mathrm{DC}$ & DD & & \\
\hline (1) & (2) & (3) & (4) & (5) & (6) & (7) \\
\hline $\mathrm{CC}$ & 146 & 7 & 15 & 4 & 1 & 173 \\
\hline CD & 8 & 3 & 14 & 11 & 0 & 36 \\
\hline $\mathrm{DC}$ & 6 & 12 & 8 & 17 & 1 & 44 \\
\hline DD & 9 & 12 & 5 & 74 & 7 & 107 \\
\hline Sum & 169 & 34 & 42 & 106 & 9 & 360 \\
\hline
\end{tabular}

\subsection{Analysis of Dyads}

Our main focus in this subsection is on in-dyad dynamics. We first investigate how mutual cooperation is affected by asymmetry and payoff structures. We then study the behavior of player types over treatments.

Strategic interactions in our three treatments are summarized in tables 5 3. Column 1 shows the four possible choice combinations of both players. The first letter characterizes player $i$ 's choice, e.g. $D C$ reads that player $i$, the hightype player in ASYM, defected $(D)$ and player $j$, the low-type player in ASYM, cooperated $(C)$. Columns 2 - 5 display how players responded to the move in the previous period aggregated over the first 39 periods. Column 6 shows choices in the last period separately because no move followed.

Table 5 presents strategic reactions in ASYM while tables 4 and 3 deal with LOW and HIGH respectively. For instance $C C$ is followed by $C C$ in ASYM with a probability of $0.859\left(67 / 78^{32}\right)$, in LOW with a probability of $0.957(224 / 234)$ and in HIGH with a probability of 0.849 (146/172). Although the tables are informative, they cannot be used as a basis for statistical tests as individual periods are not independent observations. All following statistical tests will therefore be

\footnotetext{
${ }^{31}$ Note that choices in each treatment sum up to 360 observations only because the two moves of both players in one period $(C C, C D, D C, D D)$ are aggregated into one observation, e.g. we have $40 \times 9=360$ aggregated choices.

${ }^{32}$ Column 7 minus column 6 , e.g. $C C: 80-2=78$.
} 
Table 4: Strategic interactions in LOW (frequencies).

\begin{tabular}{|c|c|c|c|c|c|c|}
\hline \multirow[t]{2}{*}{ dyad } & \multicolumn{4}{|c|}{ followed by } & \multirow[t]{2}{*}{ 40th period } & \multirow[t]{2}{*}{ Sum } \\
\hline & $\mathrm{CC}$ & CD & $\mathrm{DC}$ & DD & & \\
\hline (1) & $(2)$ & (3) & (4) & (5) & (6) & (7) \\
\hline $\mathrm{CC}$ & 224 & 7 & 2 & 1 & 1 & 235 \\
\hline CD & 1 & 6 & 1 & 14 & 1 & 23 \\
\hline $\mathrm{DC}$ & 5 & 4 & 0 & 1 & 1 & 11 \\
\hline DD & 2 & 2 & 7 & 74 & 6 & 91 \\
\hline Sum & 232 & 19 & 10 & 90 & 9 & 360 \\
\hline
\end{tabular}

Table 5: Strategic interactions in ASYM (frequencies).

\begin{tabular}{l|cccccc}
\hline dyad & \multicolumn{4}{|c}{ followed by } & 40th period & Sum \\
& CC & CD & DC & DD & & \\
\hline \hline$(1)$ & $(2)$ & $(3)$ & $(4)$ & $(5)$ & $(6)$ & $(7)$ \\
\hline CC & 67 & 9 & 2 & 0 & 2 & 80 \\
CD & 3 & 11 & 25 & 26 & 1 & 66 \\
DC & 7 & 16 & 13 & 17 & 0 & 53 \\
DD & 2 & 26 & 9 & 118 & 6 & 161 \\
\hline Sum & 79 & 62 & 49 & 161 & 9 & 360
\end{tabular}

based on dyad-level (independent) observations.

We first test whether asymmetry influences mutual cooperation.

RESULT 2: Symmetry has a positive effect on mutual cooperation.

SUPPORT: For this test, we compute the percentage of $C C$-choices in each group. We then compare the resulting 9 independent observations across treatments. The null hypothesis is that $p(C C \mid S Y M)=p(C C \mid A S Y M)$. The Mann-Whitney $\mathrm{U}$ test $(p \leq 0.015$; one-sided) yields a significant difference in that the frequency of cooperative dyads is significantly higher in SYM than in ASYM. ${ }^{33}$

We next test whether the different payoff structures in the symmetric treatments HIGH and LOW influence mutual cooperation.

\footnotetext{
${ }^{33}$ The tests for HIGH vs. ASYM and LOW vs. ASYM are $(p \leq 0.056$; one-sided $)$ and ( $p \leq 0.020$; one-sided) respectively.
} 
RESULT 3: Differences in mutual cooperation between HIGH and LOW are not statistically significant.

SUPPORT: The null hypothesis is that $p(C C \mid H I G H)=p(C C \mid L O W)$. The Mann-Whitney $\mathrm{U}$ test ( $p \leq 0.245$; one-sided) yields no statistical difference between LOW and HIGH.

RESULT 4: Asymmetry reduces the stability of mutual cooperation.

SUPPORT: Long sequences of mutual cooperation (i.e. more than 20 periods) are extremely rare in ASYM (1 out of 9 dyads), whereas such long sequences are found 4 times in HIGH and 7 times in LOW. A Fisher exact test shows that this difference is significant ( $p \leq 0.018$; one-sided). There is, however, no significant difference between the symmetric treatments ( $p \leq 0.167$; one-sided). Again, these findings clearly indicate that symmetry matters for the stability of cooperation. RESULT 5: Mutual cooperation is more frequently followed by mutual cooperation in SYM than in ASYM.

SUPPORT: We compute for each dyad the relative frequencies of CC-moves followed by CC-moves, i.e. the left most cells in table 3 - 5 for each group. A Mann-Whitney U test comparing 18 dyads in SYM and 9 dyads in ASYM yields ( $p \leq 0.043$; one-sided). The same test yields ( $p \leq 0.370$; two-sided $)$ comparing HIGH and LOW, $(p \leq 0.014$; one-sided) comparing ASYM and LOW and ( $p \leq 0.212$; one-sided) comparing ASYM and HIGH. ${ }^{34}$ Thus, the stability of cooperation once reached is higher in SYM than in ASYM, and higher in LOW than in ASYM. No significant difference can be found between HIGH and LOW and between ASYM and LOW.

Based on Pruitt's considerations on integrative solutions and the experimental results by Schellenberg (1964), Sheposh and Gallo (1973) and Talley (1974), occasional defection of low-type players in ASYM might be tolerated to a greater

\footnotetext{
${ }^{34} \mathrm{~A}$ corresponding Fisher-Pitman permutation test yields ( $p \leq 0.014$; one-sided) for SYM vs. ASYM ( $p \leq 0.072$; one-sided) for HIGH vs. ASYM, ( $p \leq 0.011$; one-sided $)$ for LOW vs. ASYM and ( $p \leq 0.351$; two-sided) for LOW vs. HIGH.
} 
extent than defection in the SYM treatments. We therefore investigate whether the player type has an impact on the pattern of cooperation. Are low-type players more likely to shift from mutual cooperation to one-sided defection than high-type players?

Observation 1: Low-type players are more likely to defect after mutual cooperation than high-type players.

SUPPORT: Over all 9 dyads, mutual cooperation is maintained in 67 cases (see table 5. Mutual cooperation never directly leads to mutual defection in the succeeding period. One-sided defection after mutual cooperation is observed 9 times for low-type players $(C D)$ and only 2 times for high-type players $(D C)$. From the 9 dyads, 3 dyads exhibit no mutual cooperation and 1 dyad has no defections after mutual cooperation (see Appendix A). One-sided defection of low-type players is observed in 3 dyads, while one-sided defection of high-types is observed only once. In one dyad, both types of one-sided defection can be observed once. The cooperation rate of $38.75 \%$ in ASYM is due to low-type players cooperating $36.9 \%$ and high-type players cooperating $40.6 \%$. Cooperation rates in LOW and $\mathrm{HIGH}$ are $70 \%$ and $59.17 \%$ respectively.

We now analyze whether high-type players are more likely to choose cooperatively after mutual defection than low-type players.

Observation 2: High-type players are more likely to initiate cooperation after mutual defection than low-type players.

SUPPORT: We compare cooperation behavior of high-type and low-type players after mutual defection. Over all 9 dyads, high-type players choose cooperatively after mutual defection in 28 cases while this happens only 11 times with low-type players (see table 5). We tested the null-hypothesis that the probability of CD and $\mathrm{CC}$ after mutual defection (6 dyads) equals the probability of DC and CC after mutual cooperation (2 dyads), i.e. $p\left(C D_{t} \cup C C_{t} \mid D D_{t-1}\right)=p\left(D C_{t} \cup C C_{t} \mid\right.$ $\left.D D_{t-1}\right)=0.5$. Over all 9 dyads, mutual defection is followed by cooperation of the high-type player in 6 dyads and by cooperation of the low-type player 
in 2 dyads. In one dyad, deviations from mutual defection never occurred (see Appendix A). Even though a Binomial test does not show a significant result ( $p \leq 0.145$, one-sided), there is a tendency that high-type players are more likely to choose cooperatively after mutual defection than low-type players.

\subsection{Analysis of Alternating Strategies}

Instead of playing the subgame-perfect equilibrium of $D D$ minimizing the payoff difference $^{35}$ or the cooperative solution of $\mathrm{CC}$ maximizing joint payoff ${ }^{36}$ in all 40 periods, players may pursue different goals in asymmetric games. Players may try to even out the asymmetric payoff structure and aim for equal payoffs (c.f. de Herdt (2003)). ${ }^{37}$ In our setting, equal payoffs are attainable by a rather complicated alternation pattern: if the high-type player cooperates all the time, and the low-type player defects in every fourth period both players get an average per-period payoff of $9 .^{38}$

We found only one dyad (number 7 ) that succeeded in establishing an alternation sequence yet providing a Pareto inferior solution without achieving payoff equality (see appendix A). The coordinated strategy of alternating between $D C$ and $C D$ in each period, thus yielding an average per-period payoff of 6 to the low-type player and of 9 to the high-type player was much simpler and the pattern lasted for the final 20 periods. ${ }^{39}$

\footnotetext{
$35(40 \times 6)+(40 \times 4)=400$, payoff difference 80 .

${ }^{36}(40 \times 12)+(40 \times 8)=800$, payoff difference 160 .

${ }^{37}$ See also the literature on inequity aversion, for instance Fehr and Schmidt (1999) or Bolton and Ockenfels (2000).

${ }^{38}$ Playing $C C$ for three periods gives 36 to the high-type player and 24 to the low-type player. Playing $C D$ in the fourth period adds another 12 to the low-type's account.

${ }^{39}$ There exist a few failed attempts of other groups that could be interpreted as trying to establish an alternation pattern.
} 


\section{Conclusion}

The basic hypothesis analyzed in this paper concerns the frequency of cooperative play in asymmetric (ASYM) versus symmetric (HIGH and LOW) PD games. As conjectured we find asymmetry to reduce cooperation rates by up to 41 percentage points. LOW induces the highest cooperation rates followed by HIGH and finally ASYM with significantly lower cooperation rates. Moreover, cooperation rates in ASYM increase with a substantial delay compared to other treatments.

From the evidence gathered it seems that in symmetric games individual players' ranking of outcomes is likely to be the same for both players. In asymmetric games, however, this seems not to be the case because for the low-type player the $C C$-outcome in all periods may not be as attractive thereby rendering coordination on a mutually compatible outcome more difficult. In particular, player's perception of what constitutes a fair outcome is likely to diverge. In the asymmetric PD, low-type and high-type players appear to have a different initial understanding of what constitutes a mutually acceptable outcome (or series of outcomes, for example in an alternation strategy) reducing cooperation rates. It appears that equality arguments are important and depend on the relative position of the player. As a low-type player, occasional defection may be a salient choice, "justified" by the idea that this redresses the unmotivated asymmetry in payoffs. This is in line with the finding by Roth and Malouf (1979) and Roth and Murnighan (1982) from bargaining experiments. They found that bargaining strategies depend on the counterpart's payoffs. In particular the low-type position is used to argue for special advantages. ${ }^{40}$ High-type players may in contrast initially focus on mutual cooperation as the salient choice rejecting responsibility for the assignment of types that low-types try to redress. Such a self-serving bias resulting from the lack of a mutually acceptable salient outcome reduces

\footnotetext{
${ }^{40}$ As found in Talley (1974), information about other player's payoffs has a positive effect on cooperation in symmetric games while decreasing cooperation of low-types in asymmetric games.
} 
cooperation. $^{41}$

Although cooperation rates in ASYM eventually increase, indicating some coordination of strategies, they do not reach the levels found in symmetric games. Essentially, asymmetry reduces the frequency of cooperation and the stability of cooperation in dyads. Low-type players are more likely to defect after mutual cooperation than high-types, and high-types initiate cooperation more often than low-types. From this perspective, there seems to be at least a tendency to accommodate lower payoffs by low-types.

In our design asymmetry is imposed without being specifically motivated. This may allow low-types to insist on occasional defection not being counted as such (entailing no retaliation by high-types) because the assignment of the highor low-type position may be perceived as arbitrary. If asymmetry is motivated and motivation is treated as an experimental design variable this line of argument could further be tested. An experimental study designed along these lines may allow the manipulation of fairness norms and is an important issue for further research.

\footnotetext{
${ }^{41}$ See Babcock et al. (1995) and Babcock and Loewenstein (1997) for a discussion of the negative effects of self-serving biases in bargaining.
} 


\section{References}

Andreoni, J. and Miller, J. H. (1993). Rational cooperation in the finitely repeated prisoner's dilemma: Experimental evidence. Economic Journal, 103:570-585.

Andreoni, J. and Varian, H. (1999). Preplay contracting in the prisoners' dilemma. Proceedings of the National Academy of Sciences of the United States of America, 96:10933-10938.

Axelrod, R. (1984). The Evolution of Cooperation. Basic Books, New York.

Babcock, L. and Loewenstein, G. (1997). Explaining bargaining impasse: The role of self-serving biases. Journal of Economic Perspectives, 11(1):109-126.

Babcock, L., Loewenstein, G., Issacharoff, S., and Camerer, C. (1995). Biased judgements of fairness in bargaining. American Economic Review, 85(5):1337-1343.

Binmore, K. (1992). Fun and Games. A Text on Game Theory. Lexington, MA: Heath.

Bolton, G. E. and Ockenfels, A. (2000). A theory of equity, reciprocity and competition. American Economic Review, 100:166-193.

Brenner, T. and Hennig-Schmidt, H. (2006). Belief learning in the prisoner's dilemma game - an experimental study of cognitive processes. Discussion paper, University of Bonn.

Charness, G., Fréchette, G. R., and Qin, C.-Z. (2007). Endogenous transfers in the prisoner's dilemma game: An experimental test of cooperation and coordination. Discussion paper, forthcoming in Games and Economic Behavior.

Croson, R. T. A. (1999). The disjunction effect and reason-based choice in games. Organizational Behavior and Human Decision Processes, 80:118-133.

de Herdt, T. (2003). Cooperation and fairness: The Flood-Dresher experiment revisited. Review of Social Economy, 56:183-210.

de Jasay, A., Güth, W., Kliemt, H., and Ockenfels, A. (2004). Take or leave? Distribution in asymmetric one-off conflict. Kyklos, 57:217-236.

Fehr, E. and Schmidt, K. M. (1999). A theory of fairness, competition and cooperation. Quarterly Journal of Economics, 14:815-868.

Fehr, E. and Schmidt, K. M. (2003). Theories of fairness and reciprocity - evidence and economic applications. In Dewatripont, M., Hansen, L. P., and Turnovsky, S. J., editors, Advances in Economics and Econometrics, pages 208-257, Cambridge. Cambridge University Press.

Fischbacher, U. (1999). Z-tree. Zürich toolbox for readymade economic experiments. Discussion paper, University of Zürich.

Flood, M. M. (1958). Some experimental games. Management Science, 5:5-26. 
Friederiszick, H. W. and Maier-Rigaud, F. P. (2007). Triggering inspections ex officio: Moving beyond a passive EU cartel policy. Journal of Competition Law and Economics. forthcoming.

Güth, W., Kliemt, H., and Ockenfels, A. (2003). Fairness versus Efficiency: An Experimental Study of (Mutual) Gift Giving. Journal of Economic Behavior and Organization, 50:465-475.

Hennig-Schmidt, H. (2002). The impact of fairness on decision making - an analysis of different video experiments. In Andersson, F. and Holm, H., editors, Experimental Economics, Financial Markets, Auctions and Decision Making, pages 185-210. Kluwer Academic Publishers, Dordrecht.

Kahnemann, D. and Tversky, A. (1979). Prospect theory: An analysis of decision under risk. Econometrica, 47:263-292.

Kaiser, J. (2007). An exact and a Monte Carlo proposal to the Fisher-Pitman permutation tests for paired replicates and for independent samples. Discussion paper, University of Bonn.

King, T. R. and Murnighan, J. K. (1988). Stability and outcome tradeoffs in asymmetric dilemmas: Conditions promoting the discovery of alternating solutions. In Tietz, R., Albers, W., and Selten, R., editors, Bounded Rational Behavior in Experimental Games and Markets, pages 85-94. Springer Verlag, Berlin.

Lave, L. B. (1965). Factors affecting co-operation in the prisoner's dilemma. Behavioral Science, 10:26-38.

Ledyard, J. O. (1995). Public Goods: A Survey of Experimental Research. In Kagel, J. H. and Roth, A. E., editors, The Handbook of Experimental Economics. Princeton, NJ: Princeton University Press.

Luce, R. D. and Raiffa, H. (1957). Games and Decisions. New York: Wiley.

Maier-Rigaud, F. P. and Apesteguia, J. (2006). Assignment versus choice in prisoner's dilemma experiments. Discussion paper, Max Planck Institute for Research on Collective Goods.

McKeown, C. D., Gahagan, J. P., and Tedeschi, J. T. (1967). The effect of prior power strategy on behavior after a shift of power. Journal of Experimental Research in Personality, 2:226-233.

Murnighan, J., King, T. R., and Schoumaker, F. (1990). The dynamics of cooperation in asymmetric dilemmas. In Lawler, E., Markovsky, B., Ridgeway, C., and Walker, H., editors, Advances in Group Processes, number 7, pages 179-202. JAI Press, Greenwich, Conn.

Murnighan, J. K. (1991). Cooperation when you know your outcomes will differ. Simulation and Gaming, 22:463-475. 
Murnighan, J. K. and King, T. R. (1992). The effects of leverage and payoffs on cooperative behavior in asymmetric dilemmas. In Liebrand, W. B. G., editor, Social Dilemmas, Theoretical Issues and Research Findings, pages 163-182. Pergamon Press.

Osborne, M. J. and Rubinstein, A. (1994). A Course in Game Theory. Cambridge: MIT Press.

Oskamp, S. (1971). Effects of programmed strategies on cooperation in the prisoner's dilemma and other mixed-motive games. Journal of Conflict Resolution, $15(2): 225-259$.

Ostrom, E. (1990). Governing the Commons. The Evolution of Institutions for Collective Action. Cambridge: Cambridge University Press.

Pruitt, D. G. (1967). Reward structure of cooperation: The decomposed prisoner's dilemma game. Journal of Personality and Social Psychology, 7:21-27.

Pruitt, D. G. (1970). Motivational processes in the decomposed prisoner's dilemma game. Journal of Personality and Social Psychology, 14:227-238.

Pruitt, D. G. (1981). Negotiation Behavior. Academic Press.

Rapoport, A. and Chammah, A. M. (1965). Prisoner's Dilemma: A Study in Conflict and Cooperation. University of Michigan Press, Ann Arbor.

Roth, A. E. (1995). Introduction to experimental economics. In Kagel, J. H. and Roth, A. E., editors, The Handbook of Experimental Economics, pages 3-109. Princeton University Press, Princeton, New Jersey.

Roth, A. E. and Malouf, M. W. K. (1979). Game theoretic models and the role of information in bargaining. Psychological Review, 86:574-594.

Roth, A. E. and Murnighan, J. K. (1978). Equilibrium behavior and repeated play of the prisoner's dilemma. Journal of Mathematical Psychology, 17:189-198.

Roth, A. E. and Murnighan, J. K. (1982). The role of information in bargaining: An experimental study. Econometrica, 50:1123-1142.

Schellenberg, J. A. (1964). Distributive justice and collaboration in non-zero-sum games. Journal of Conflict Resolution, 8(2):147-150.

Selten, R. and Stoecker, R. (1986). End behavior in sequences of finite prisoner's dilemma supergames. Journal of Economic Behavior and Organization, 7:47-70.

Sheposh, J. P. and Gallo, P. S. (1973). Asymmetry of payoff structure and cooeprative behavior in the prisoner's dilemma game. Journal of Conflict Resolution, 17:321333.

Talley, M. B. (1974). Effects of Asymmetry of Payoff and Asymmetry of Information in a Prisoner's Dilemma Game. PhD thesis, University of Texas at Arlington. 
Tversky, A. and Kahnemann, D. (1981). The framing of decisions and the psychology of choice. Science, 211:453-458. 
APPENDIX A: Choices in all Dyads
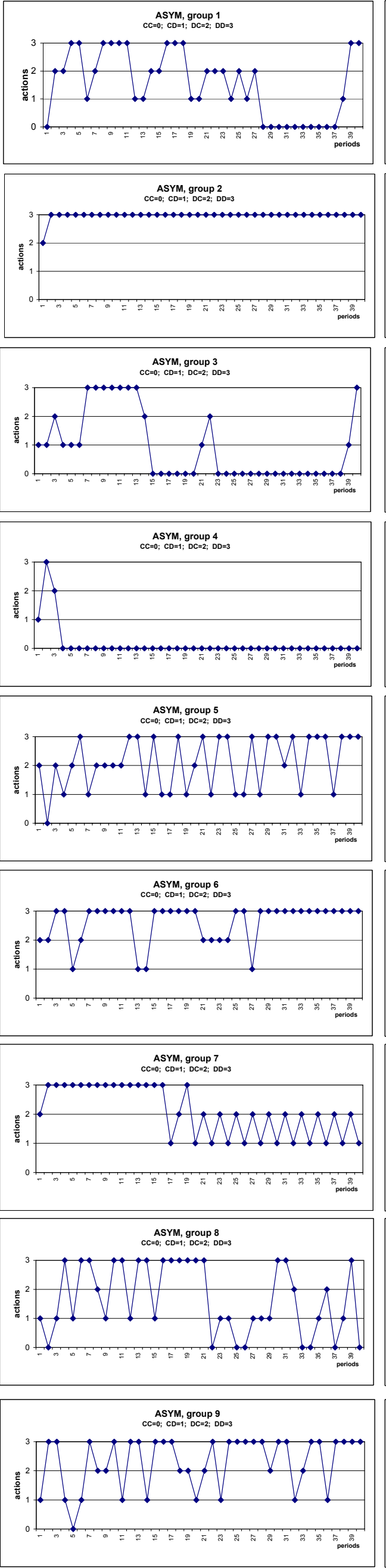
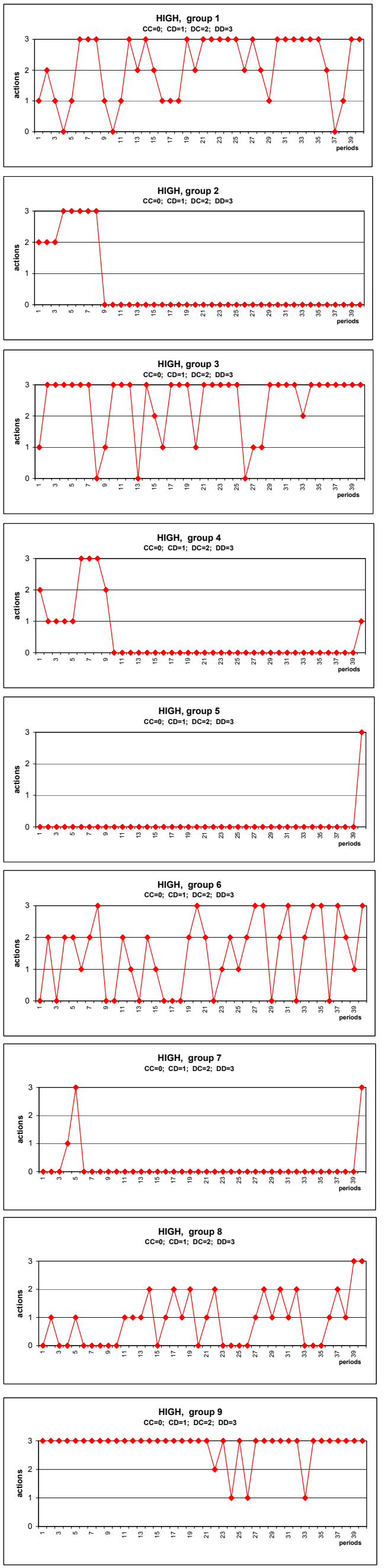
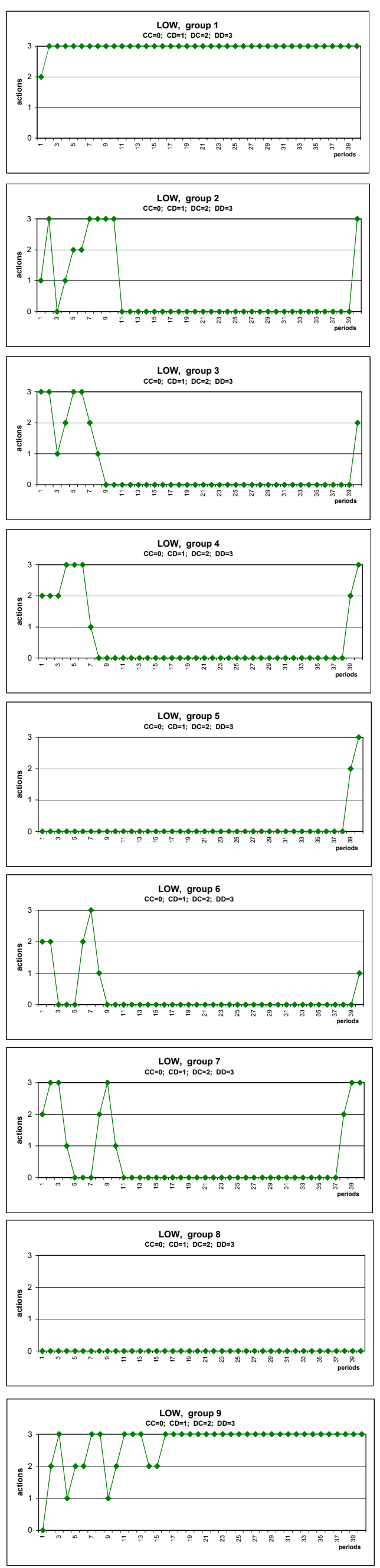


\section{APPENDIX B: Instructions}

[In All Treatments]

\section{Note:}

- You have 5 minutes to read the instructions. If you have any questions after you have read the instructions, please contact one of the experimenters. Communication with other participants is not allowed during the experiment.

- After the 5 minutes you will be asked to fill out a test questionnaire about the experiment you will be part in. Once all participants have correctly answered all questions, the experiment will start.

- After completion of the experiment you will be asked to complete a computerized questionnaire

- Please do not leave your seat before you have filled out the questionnaire and your terminal number has been announced

\section{The experiment:}

The experiment consists of a decision situation in which you and another person will choose between A and B for 40 periods. Your position as well as the person you are interacting with is randomly assigned to you at the beginning of the experiment. The decision situation, as well as the person you interact with is identical in each period. You will see the decision made by the other person in each period after you made your own decision.

In each period, by deciding between a choice of A or B, you can decide the amount of Taler that you and the other person will receive. The following graph depicts the decision screen, you will see during the experiment.

In the left half you see the consequences of your own two decision options and below your decision buttons.

In the right half of the screen you see the decision options of the other person. 
[In the LOW treatment only]

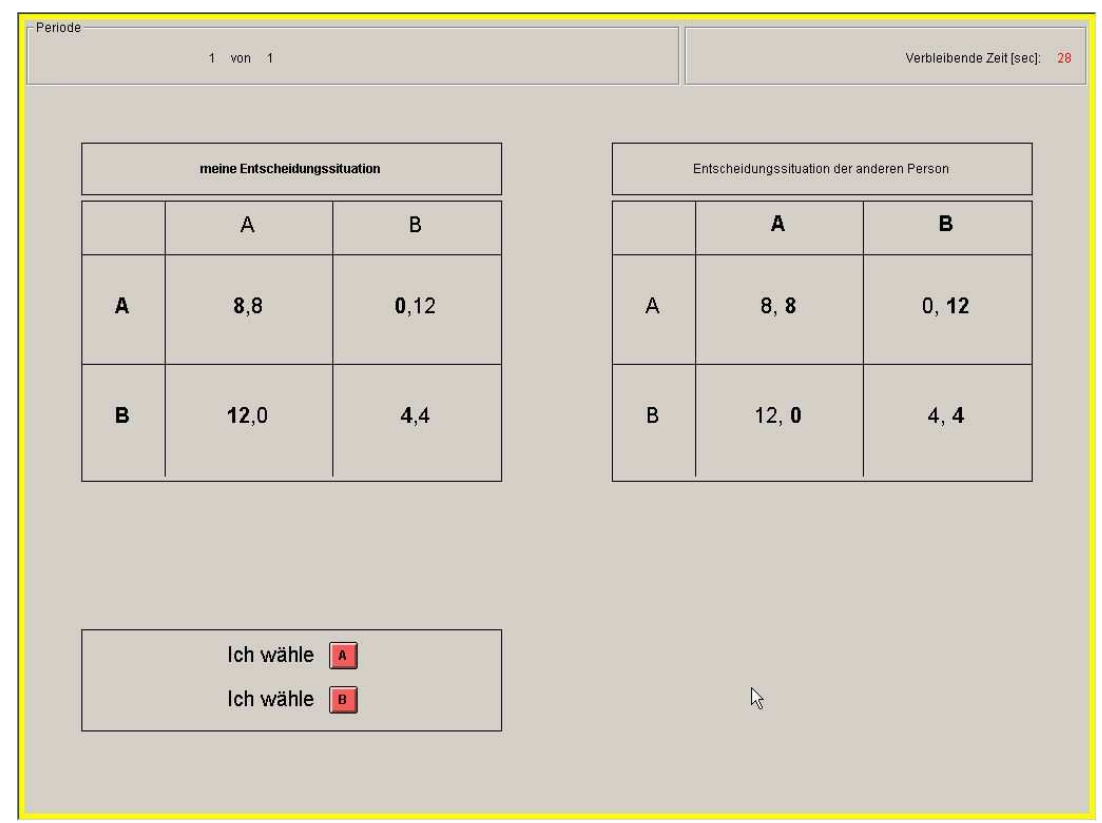

The amount of Talers you earn in each period depends on your and the other persons decision:

- If you choose A and the other person as well, you both receive 8 .

- If you choose B and the other person as well, you both receive 4.

- If you choose $\mathrm{A}$ and the other person chooses $\mathrm{B}$, you receive 0 and the other person receives 12 .

- If you choose B and the other person chooses A you receive 12 and the other person receives 0 . 
[In the HIGH treatment only]

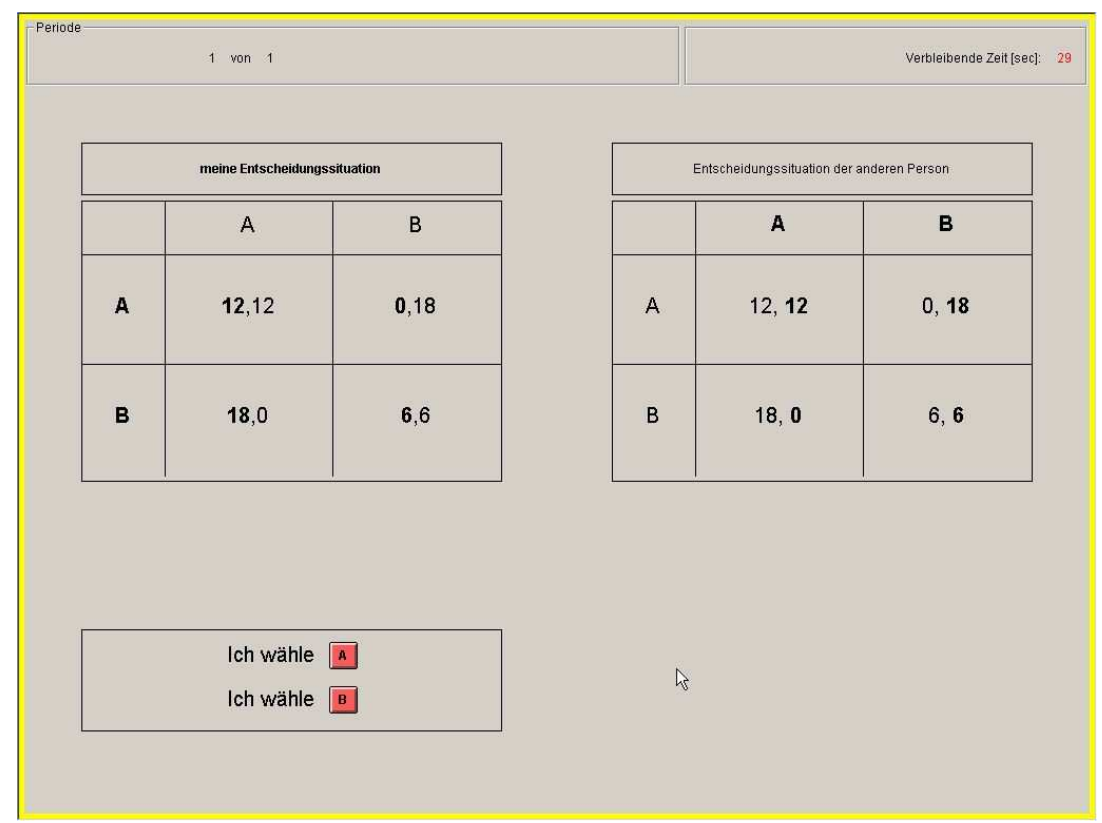

The amount of Talers you earn in each period depends on your and the other persons decision:

- If you choose A and the other person as well, you both receive 12 .

- If you choose B and the other person as well, you both receive 6 .

- If you choose $\mathrm{A}$ and the other person chooses $\mathrm{B}$, you receive 0 and the other person receives 18 .

- If you choose B and the other person chooses A you receive 18 and the other person receives 0 . 
[In the ASYM treatment for the low-type player only]

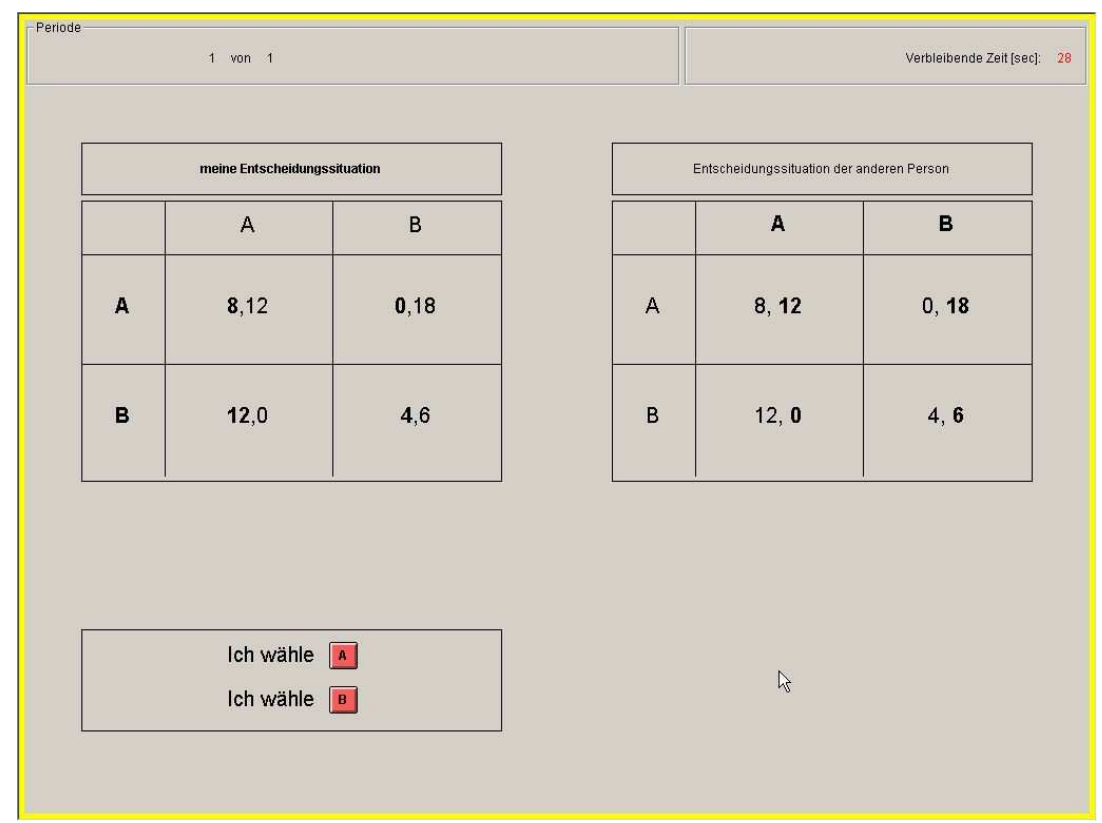

The amount of Talers you earn in each period depends on your and the other persons decision:

- If you choose $\mathrm{A}$ and the other person as well, you receive 8 and the other person receives 12 .

- If you choose $\mathrm{B}$ and the other person as well, you receive 4 and the other person receives 6 .

- If you choose $\mathrm{A}$ and the other person chooses $\mathrm{B}$, you receive 0 and the other person receives 18 .

- If you choose $\mathrm{B}$ and the other person chooses $\mathrm{A}$ you receive 12 and the other person receives 0 . 
[In the ASYM treatment for the high-type player only]

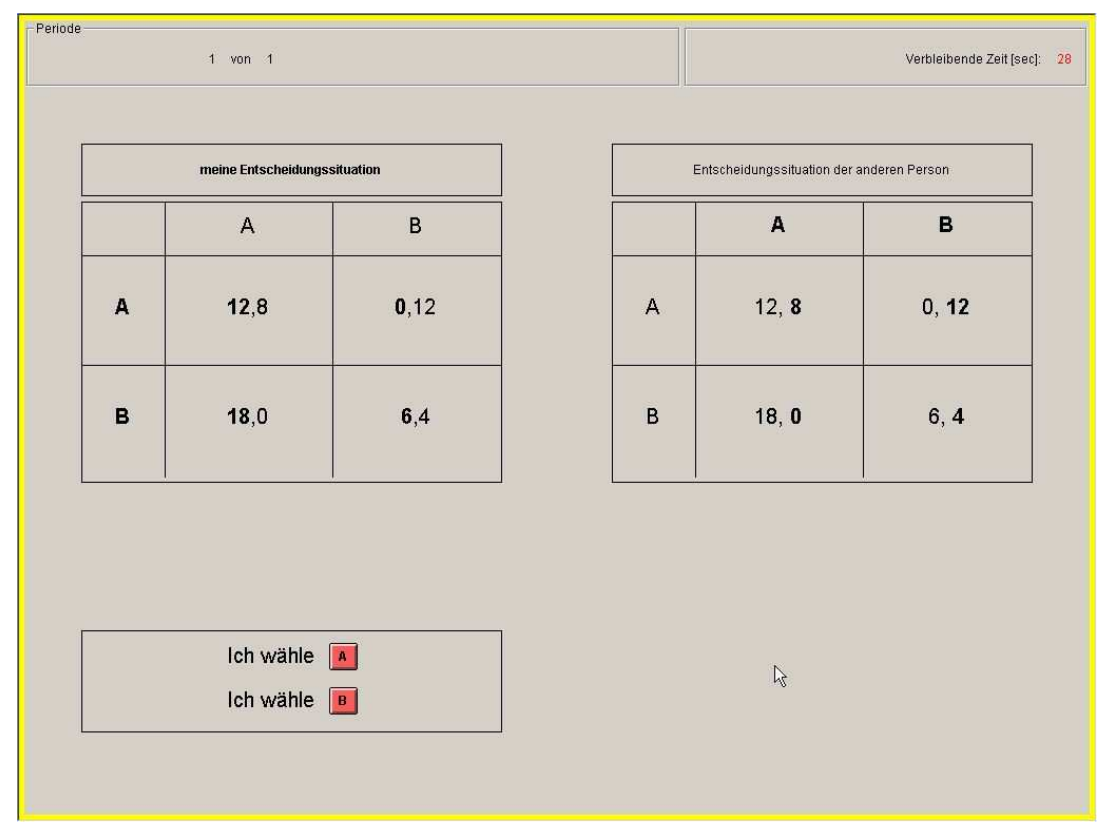

The amount of Talers you earn in each period depends on your and the other persons decision:

- If you choose A and the other person as well, you receive 12 and the other person receives 8 .

- If you choose B and the other person as well, you receive 6 and the other person receives 4 .

- If you choose $\mathrm{A}$ and the other person chooses $\mathrm{B}$, you receive 0 and the other person receives 12 .

- If you choose $\mathrm{B}$ and the other person chooses $\mathrm{A}$ you receive 18 and the other person receives 0 .

[In all treatments]

After each period you will be given information on: your last decision, the last decision of the other person, the number of Talers you earned in the last period, and the total number of Talers you have earned so far.

\section{Payment:}

The total number of Taler earned will be paid out anonymously to you at the end of the experiment 1 Taler corresponds to 0.04 Euro.

Thank you very much for your participation! 


\section{APPENDIX D: The Computerized Questionnaire}

\begin{tabular}{l|l}
\hline \hline Question $\sharp$ & Question \\
\hline 1 & Terminal number? \\
2 & Major? \\
3 & Job? \\
5 & Semester? \\
6 & Age? \\
7 & Sex? \\
8 & Did you ever take a microeconomics course? \\
9 & Did you ever take a game theory class? \\
10 & Please describe briefly the reasons for your choices \\
11 & Did your decision behavior change during the experiment? If yes, how? \\
12 & I believe that the main goal of this experiment was to maximize my \\
& own advantage [I fully agree, I strongly disagree] \\
13 & I believe that the main goal of this experiment was to maximize the \\
& group advantage [I fully agree, I strongly disagree] \\
14 & What daily life situation did this experimental situation remind \\
& you of the most? \\
\hline
\end{tabular}




\section{APPENDIX E: The Test Questions}

- How high is the profit of the other person, if she chooses A and you too?

- How high is your profit, if you choose B and the other person A?

- How high is the profit of the other person, if she chooses A and you $\mathrm{B}$ ?

- How high is your profit, if you choose A and the other person too?

- How high is the profit of the other person, if she chooses B and you too?

- How high is your profit, if you choose B and the other person too?

- How high is the profit of the other person, if she chooses B and you choose A?

- How high is your profit, if you choose A and the other person chooses $\mathrm{B}$ ? 


\section{Max Planck Institute for Research on Collective Goods}

\section{Preprints 2006}

150. Felix Bierbrauer, Collectively Incentive Compatible Tax Systems. 2006/24.

149. Sven Fischer / Andreas Nicklisch, Ex Interim Voting in Public Good Provision. 2006/23.

forthcoming in:

Journal of Institutional and Theoretical Economics 2007.

148. Martin Hellwig, Private Damage Claims and the Passing-On Defense in Horizontal Price-Fixing Cases: An Economist's Perspective. 2006/22.

forthcoming in:

Jürgen Basedow (ed.), Private Enforcement of EC Competition Law, The Hague: Kluwer Law International, 2007.

147. Martin Hellwig, The Provision and Pricing of Excludable Public Goods: Ramsey-Boiteux Pricing versus Bundling. 2006/21.

forthcoming in:

Journal of Public Economics

146. Martin Hellwig, Effizienz oder Wettbewerbsfreiheit? Zur normativen Grundlegung der Wettbewerbspolitik. 2006/20.

published in:

Christoph Engel/Wernhard Möschel (eds.): Recht und spontane Ordnung. Festschrift für

Ernst-Joachim Mestmäcker zum 80. Geburtstag. Nomos-Verlag Baden-Baden 2006, 231-268.

145. Christoph Engel / Elke U. Weber, The Impact of Institutions on the Decision How to Decide. 2006/19.

144. Felix Bierbrauer / Marco Sahm, Informative Voting and the Samuelson Rule. 2006/18.

143. Andreas Nicklisch. Perceiving strategic environments: An experimental study of learning under minimal information. 2006/17.

142. Felix Höffler: Mobile termination and collusion, revisited. 2006/16.

141. Ingolf Schwarz: Monetary Equilibria in a Baumol-Tobin Economy. 2006/15.

140. Martin Beckenkamp: The herd moves? Emergence and self-organization in collective actors. 2006/14.

139. Christoph Engel: Herrschaftsausübung bei offener Wirklichkeitsdefinition. Das Proprium des Rechts aus der Perspektive des öffentlichen Rechts. 2006/13.

forthcoming in:

Christoph Engel/Wolfgang Schön: Das Proprium der Rechtswissenschaft. Mohr (Siebeck) Tübingen 2007.

138. Christoph Engel: Wettbewerb als sozial erwünschtes Dilemma. 2006/12.

published in:

Christoph Engel/Wernhard Möschel (eds.): Recht und spontane Ordnung. Festschrift für Ernst-Joachim Mestmäcker zum 80. Geburtstag. Nomos-Verlag Baden-Baden 2006, , 155-198.

137. Hendrik Hakenes / Isabel Schnabel: The Threat of Capital Drain: A Rationale for Public Banks? 2006/11.

136. Martin Hellwig: Zur Kategorie der Kausalität in den Wirtschaftswissenschaften. 2006/10.

135. Felix Höffler / Madjid Kübler: Demand for storage of natural gas in northwestern Europe. A simulation based forecast 2006-2030. 2006/9. 
134. Dorothea Alewell / Andreas Nicklisch: Wage Differentials, Fairness and Social Comparison: An experimental study of the Co-Employment of Permanent and Temporary Agency Workers. 2006/8.

133. Stefan Magen, Zur Interaktion von Recht und sozialen Normen bei der dezentralen Bereitstellung von Gemeinschaftsgütern. 2006/7.

132. Felix Bierbrauer, Distortionary Taxation and the Free-Rider Problem. 2006/6.

131. Felix Höffler, Tobias Wittmann, Netting of capacity in interconnector auctions. 2006/5.

130. Eyal Ert / Andreas Nicklisch, Noisy commitments: The impact of information accuracy on efficiency. 2006/4.

129. Anne van Aaken, Begrenzte Rationalität und Paternalismusgefahr: Das Prinzip des schonendsten Paternalismus. 2006/3.

forthcoming in:

Christoph Engel/Markus Englerth/Jörn Lüdemann/Indra Spiecker: Recht und Verhalten. Mohr (Siebeck) Tübingen 2007.

128. Jörn Lüdemann, Die Grenzen des homo oeconomicus und die Rechtswissenschaft. 2006/2.

forthcoming in:

Christoph Engel/Markus Englerth/Jörn Lüdemann/Indra Spiecker: Recht und Verhalten. Mohr (Siebeck) Tübingen 2007.

127. Christoph Engel, The Difficult Reception of Rigorous Descriptive Social Science in the Law. 2006/1. 